\title{
The ethics of emergencies
}

\author{
Aksel Braanen Sterri ${ }^{1}$ (D) Ole Martin Moen ${ }^{1,2}$
}

Accepted: 29 September 2020/Published online: 9 October 2020

(C) The Author(s) 2020

\begin{abstract}
Do we have stronger duties to assist in emergencies than in nonemergencies? According to Peter Singer and Peter Unger, we do not. Emergency situations, they suggest, merely serve to make more salient the very extensive duties to assist that we always have. This view, while theoretically simple, appears to imply that we must radically revise common-sense emergency norms. Resisting that implication, theorists like Frances Kamm, Jeremy Waldron, and Larry Temkin suggest that emergencies are indeed normatively exceptional. While their approach is more in line with common-sense, however, it is theoretically less simple, and it is has proven difficult to justify the exception. In this paper we propose a model of emergencies that we call the Informal-Insurance Model, and explain how this can be used to combine theoretical simplicity with common-sense emergency norms.
\end{abstract}

Keywords Charity - Consequentialism - Duties of assistance - Effective altruism . Emergencies · Insurance

\section{Introduction}

Emergencies have become the bread and butter of practical ethics. In journals and seminar rooms, we are discussing whether it would be right to divert a runaway trolley to kill one instead of five, how much we must sacrifice to save a child

Ole Martin Moen

olemarti@oslomet.no

Aksel Braanen Sterri

aksel.sterri@ifikk.uio.no

1 Department of Philosophy, Classics, History of Art and Ideas, University of Oslo, Box 1020, Blindern, 0315 Oslo, Norway

2 Faculty of Health Sciences, Oslo Metropolitan University, Box 4, St. Olavs plass, 0130 Oslo, Norway 
drowning in a shallow pond, and whether it would be right to torture a terrorist in order to save thousands from a ticking bomb. ${ }^{1}$ Presumably, we want to figure out how it is right to act in such situations not because we think it is important to be prepared for the unlikely event that we will ever find ourselves in one of them, but because we believe that we can gain more general insights from considering emergency cases. Emergency cases, we think, put our principles to the test.

On the face of it, however, it seems problematic to use emergency cases to test our general ethical principles, since emergencies, perhaps even by definition, are cases out of the ordinary. Emergencies are exceptional circumstances in which special rules and norms apply. On the one hand, more is permissible in the case of emergencies: we may, for example, rightfully break the speed limit in order to rush someone to the hospital. On the other hand, more is mandatory: we might have a duty to help someone who is drowning in a pond right next to us, even at a substantial cost and risk to ourselves. ${ }^{2}$

In this paper we are concerned with our duties to assist in emergencies. Do special normative principles kick into place when an emergency arises? Some theorists, such as Peter Singer (1972) and Peter Unger (1996), argue that emergencies are, in principle, just like nonemergencies. In their view, we should do the action that is expected to bring about the best consequences, and this principle applies equally in emergency and nonemergency cases alike. While this view is theoretically simple, it appears, as we shall see, to have a number of highly revisionist implications. Resisting such implications, theorists like Frances Kamm (2007), Jeremy Waldron (2000), and Temkin (2017) argue that special norms and principles apply in emergency cases. The challenge with these accounts, however, is that while they preserve common-sense emergency norms, they appear to be able to arrive at these norms only by being theoretically complicated and, possibly, ad hoc.

Our aim in this paper is to try to combine the best of both sides: to make room for common-sense emergency norms within a theoretically simple framework. After sketching the theoretically simple approach and the common-sensical approach, we investigate more closely the nature of emergencies, and propose a model that we call the informal-insurance model of emergencies. By appeal to this model, we further argue, it is possible to justify common-sense emergency norms within a theoretically simple framework.

\section{The puzzle of emergencies}

Common sense suggests that emergencies can place very significant demands on us. Consider Peter Singer's case of a child drowning in a shallow pond, which may be the most commonly discussed emergency case in contemporary philosophy. ${ }^{3} \mathrm{We}$

\footnotetext{
${ }^{1}$ For the original sources of these dilemmas, see Foot (1967), Singer (1972). Bentham (1804).

${ }^{2}$ For an interesting early discussion of emergency ethics, see Rand (1964). Rand argues that special principles apply in emergency cases, and that we cannot find out what would be right in everyday situations based on what it would be right to do in a "lifeboat situation.".

3 Singer (1972).
} 
have modernized and adapted the case to make for easier comparison with other cases:

Shallow Pond: You are walking past a shallow pond, and you see a child about to drown. You can save the child's life at no risk to your own life, but you will ruin your new clothes, your expensive smartphone and your laptop. To replace them will cost you approximately $\$ 3000$. Do you have a moral obligation to rescue the child?

In this case, it seems clear that you have a moral obligation to rescue the child. Although a $\$ 3000$ loss is significant, saving a child's life is much more important. We think that someone who decided that it was not worth the sacrifice, and thus failed to save the child, would clearly be doing something morally wrong.

Now consider this alternative case:

Effective Charity: Against Malaria Foundation (AMF) is a highly effective charity. For every additional $\$ 3000$ it receives, it can be expected to save one additional life. Do you have a moral obligation to donate $\$ 3000$ to AMF?

While most would probably concede that it would be good to donate $\$ 3000$ to AMF, our duty in this case, it seems, is far weaker than our duty to save the child who is drowning in the shallow pond. To give large amounts of money to charity, most of us think, is supererogatory, i.e. good beyond what is morally mandatory. ${ }^{4}$

But why is there a moral difference between the two cases? The expected good and the expected cost, which would seem to be the two crucial features, are the same in both cases: the expected good is to save a life, and the expected cost is $\$ 3000$. In order to be justified in treating the two cases differently, however, we need to point to a morally relevant difference between the two cases.

\section{The theoretically simple approach}

According to the view that we shall call the theoretically simple approach, the same norms apply in emergency cases as in nonemergency cases.

In the debate about emergencies, the most common variant of this approach is consequentialism, which, roughly, is the view that we should always act in the way that is expected to bring about the best outcome. By appeal to consequentialism, Singer and Unger argue that we ought to help as long as we do not have to give up something of comparable moral importance, irrespective of whether we find ourselves in an emergency case. ${ }^{5}$ If we have problems being motivated as strongly to save the child dying from malaria far away as to help a child that is drowning

\footnotetext{
${ }^{4}$ In fact, most people believe people can be saved for much less than what the most effective charities can offer. See Wiblin (2017). We nevertheless abstain from donating a significant amount of money to charities.

5 Singer (1972, 241) and Unger (1996, 143).
} 
right before us, this is a failure on our part; it does not show us that saving the child dying from malaria is any less important.

Discussing emergency cases can be helpful, in their view, because such cases emphasize the very significant duties of assistance that we have towards other people. While our duties are made more salient in emergency cases, however, they are equally strong in all cases. This is a theoretically simple view that helps explain why we have strong duties to assist in emergency cases: We have strong duties to assist in emergency cases because we have strong duties to assist in general.

The problem with this solution is that to pay for the theoretical simplicity, we have to endorse a range of counterintuitive implications. On the one hand, the view has counterintuitive implications outside of emergency cases. Singer has argued that we should give away our money until the expected increase in the recipients' wellbeing equals the expected loss in your own wellbeing. ${ }^{6}$ Unger has suggested that "it's seriously wrong not to send to the likes of UNICEF and OXFAM, about as promptly as possible, nearly all your worldly wealth" to help people in extreme poverty. ${ }^{7}$ While this might be right, it seems counterintuitive.

Consequentialist views like Singer's and Unger's, moreover, also seems to yield counterintuitive implications in emergency cases. Temkin asks us to consider a case like the following:

Rolex: You have been convinced by consequentialists that you should donate money to effective charities. Your first decision is to sell your expensive and uninsured Rolex and donate the proceeds to save three children from malaria. On your way to sell it, you see a child drowning in a pond. You can only save her if you dive right in, and you have no time to remove your watch. If you save the child from drowning, you will be unable to save the other children. There is no one there, so you do not have to care about the consequences of breaking a beneficial norm. What should you do? ${ }^{8}$

In a case like this, it seems that consequentialists would have to say that we should ignore our duty to rescue and instead walk past the drowning child so that we can sell the watch, because that can be expected to save more lives. This, however, is a counterintuitive conclusion. Temkin suggests that consequentialism is counterintuitive in virtue of failing to give emergencies primacy in cases where the most good will be produced if we do not come to the rescue.

The theoretically simple views of Singer and Unger also appear to yield counterintuitive implications in a case like the following:

CEO in Car Accident: A person has been in a car accident and suffered a broken leg. Without your help, he will get nowhere. It seems that you have an obligation to drive him to the hospital, even though it is a 15-min drive in the opposite direction from where you were headed. As you are helping him into your car, however, he tells you that he is a CEO and that he wants you to drive

\footnotetext{
6 Singer (1972, 241).

7 Unger (1996, 143).

${ }^{8}$ Temkin (2017). This is a slightly modified variant of Temkin's example.
} 
him to a very important business meeting instead. This is just a 10-min detour. Getting to the business meeting on time, he argues convincingly, is more important than rushing to the hospital. He can get from the business meeting to the hospital later.

Even on the premise that the business meeting really is more important, it seems, intuitively, that our obligation is restricted to getting the CEO to the hospital. That, however, would seemingly not be the case if we must always act to bring about the best outcomes.

Thus it seems that if we accept a theoretically simple approach like that of Singer and Unger, we do not get anything close to standard emergency norms. We get nonstandard emergency norms according to which we are allowed to let the child drown in the Rolex case and we are obligated to drive the CEO to the meeting.

\section{The common-sense approach}

In light of the problems that we face if we hold that emergencies and nonemergencies should be assessed by the same standards, it is tempting to turn to views according to which emergency cases should be assessed by a different standard than other cases. It might be argued that there is something normatively special about emergencies, and that this can help justify more common-sensical moral judgments. If we have stronger duties to assist in emergencies than in nonemergencies, this could explain why it is morally worse to not save the drowning child than to not donate to the Against Malaria Foundation, morally wrong to drive past the drowning child in order to sell the Rolex, and morally permissible to refuse to drive the CEO to the board meeting.

But what, we must then ask, is it about emergencies that make them special? If one holds that emergencies should be assessed differently, one should be able to provide an explanation of why this is so since, presumably, the burden of proof is on those who posit an exception.

Waldron argues, in a discussion of the parable of the Good Samaritan, that "the key... is something like proximity, the persons in question being there, on the spot." When you are face to face with the victim, you are thereby caught in a causal nexus that grounds moral obligations: "The person that faces a victim of an emergency ha[s] to go out of their way to break the relation of sheer proximity that [generates] a perfect duty on them, also, to help."9

While it is easy to see how spatial proximity could work as a proxy, since we are usually only able to help those who are spatially close to us, it is difficult to see how less spatial proximity could, by itself, justify us in letting a person die instead of saving them. It seems that if you saw an accident through a camera when you were a thousand miles away and you could help at the same cost, you could still have emergency duties. ${ }^{10}$

\footnotetext{
9 Waldron (2000, 1075). See also Kamm (2007), Temkin (2017), Hanna (1998), Levinas (1995).

${ }^{10}$ Unger (1996, 33-34).
} 
It might, alternatively, be suggested that the scope of persons towards whom we have emergency-based duties to assist must be restricted since, otherwise, morality would be too demanding. ${ }^{11}$ While this is perhaps reasonable, it seems that emergencies can indeed place extreme demands on us. Consider the following case, adapted from Unger:

The Uninsured Bugatti: You have poured your life savings into a very expensive Bugatti that you have parked at an abandoned train station. You can't even afford to insure the car. You see a runaway trolley headed toward a trapped child. The only way you can save her is to divert the trolley to another track, where it will crush your uninsured car to pieces. ${ }^{12}$

Should you divert the runaway trolley so that it crushes your Bugatti? Even though it would leave you poor, it seems that you have a duty to sacrifice the car and save the child. If this is right, our obligations in emergencies can indeed be highly demanding. Moreover, if it were the level of demandingness that mattered-in the sense that we can only be required to assist up to a certain aggregate limit-then it would seem that, by donating money to the Against Malaria Foundation, one could exempt oneself from the duty to rescue people in emergencies. This, however, is counterintuitive: It seems that we have a duty to save the child no matter how much we have donated to the Against Malaria Foundation or how many drowning children we have already saved. ${ }^{13}$ The demandingness objection therefore seems to have difficulty explaining why we have different obligations in emergencies than in nonemergencies.

For all we argue here, it might be possible to defend a set of moral principles that can justify common-sense emergency norms. This seems, however, to be difficult, and even if it could be done, it would seem to require that we accept a set of complex, seemingly ad hoc moral duties that kick into place specifically in the case of emergencies.

In light of this, we seem to be confronted with an uncomfortable dilemma. We can choose to endorse common-sense emergency norms, but it seems that we can do so only at the cost of giving up on theoretical simplicity. Alternatively, we can choose theoretical simplicity, but it seems that we can do so only at the cost of rejecting anything resembling common-sense emergency norms.

Might it be possible to combine the best form both sides, i.e. to combine theoretical simplicity and common-sense emergency norms? We suggest that this can be done. To see how this can be possible, however, we need to look more closely into the nature of emergencies. In what follows, we first defend what we call the informal-insurance model of emergencies. This is a descriptive theory that seeks to explain common-sense emergency norms. Thereafter we show how the informalinsurance model of emergencies can be used to justify common-sense emergency norms within a theoretically simple framework. We first explain how it can justify

\footnotetext{
11 Schmidtz (2000, 2009), Woollard (2015), Sinclair (2018), Haydar and Øverland (2019).

12 Unger (1996, 136).

13 Forchehimes and Semrau (2019).
} 
common-sense emergency norms within contractarian and rule-consequentialist frameworks. Then we explain how it can justify common-sense emergency norms even within what is arguably the theoretically very simplest framework, the actconsequentialist theories of Singer and Unger.

\section{The informal-insurance model of emergencies}

What gives rise to our need for emergency norms? In order to understand why they are useful, it might be useful first to briefly zoom out and consider how different sorts of needs are sought met in different sorts of ways. On the one hand, there are needs that are most easily met by the person having the need. Your need to get dressed in the morning, for example, is usually best taken care of by you. Although some need help with getting dressed, self-dressing is the norm and other-dressing is the exception.

In the case of other types of needs, however, it makes sense that we meet them for each other. Examples could be haircuts or massages, which it is awkward to do for oneself, or goods or services that require special equipment or training, such as the production of clothes, computers, cars, and houses. Here it makes sense that we coordinate our efforts and help satisfy each other's needs. If you provide me with a haircut and I repair your car, we can both be better off than if we had tried to meet our own needs without trading. Since the beginning of the industrial revolution, more and more needs are met through the division of labor, and exchanged via money, which allows for more differentiation and specialization.

Yet other needs are of such a kind that it makes sense that we meet them through insurance. These are, in particular, relatively large needs that have to be met if we are unlucky. As a contemporary example, consider the need to get a replacement car in case one's car is stolen. Since cars can be rather expensive, most would not like to suddenly have to pay for a new car out of their own pocket in such an event. Thankfully, however, cars are not stolen very often. Let's say, for the sake of the example, that one out of every hundred cars are stolen every year. If we assume that a car costs $\$ 10,000$, then instead of having those whose cars are stolen bear the full cost, one hundred people could each pay $\$ 100$ per year in premium, and the pooled resources could be used to buy replacement cars for the two people who, statistically, have their cars stolen that year.

Not all needs are well suited to be met through insurance. Constant and predictable needs, such as your need to get your car washed when it gets dirty, are not well suited for insurance. Although it would be nice for you to have your insurance cover car washes, others who take part in the scheme would also want to have their car washes paid for this way. There is thus nothing to gain from solving this through an insurance scheme. There is, however, something to lose. For insurance to be beneficial, it is important that people do not become reckless or wasteful when insured. Without car-wash insurance, you try not to get your car dirty, and you accept it being somewhat dirty for a while. If you had insurance, however, you might not care that much about trying to prevent it from getting dirty, and once it got dirty, you might want it washed on the same day, since you would 
then share the cost with all the other insurance holders. In insurance jargon, this is called a moral hazard, and it is a problem that all insurance programs have to deal with. Insurance therefore only works when we can trust people not to take undue advantage of the fact that we collectively pay for their losses. To avoid moral hazard, we mainly insure against relatively large unforeseeable negative events that must be dealt with quickly, and there needs to be a criterion for pay-out that is unambiguous and difficult to fake.

Insurance is usually formally specified and agreed upon. In some of the cases where we suddenly and unexpectedly need help from others, however, it would be too difficult to organize the help formally, through written insurance contracts. Sometimes what we need is that the people around us step out of their ordinary routines in order to help. If you choke while eating in a restaurant, if your foot gets stuck in a railroad track, or if you are about to drown in a pond, you urgently need people around you to do what is necessary to help you escape the immediate danger. The norms that oblige us to help you in such events are emergency norms, and we suggest that they work like informal insurance schemes. You benefit from the scheme in virtue of getting help when you urgently need it. The premium that you pay to take part in this scheme is not monetary. You pay with your willingness to come to rescue in case others are in urgent need.

As in the case of formal insurance, it would be beneficial to you, as a recipient of assistance, if a wide range of negative events were covered by emergency norms. It would be convenient if others rushed to assist you if you struggled to meet a deadline on a paper, paid your restaurant bill if your account was overdrawn, or babysat your children when you had a headache. The trouble with inclusive criteria for what counts as an emergency, however, is that others would want you to rush to their assistance in similar cases. This makes inclusive emergency criteria less attractive, since it would be inconvenient if, every day, you had to stop what you're doing in order to meet all sorts of needs of the people around you. Moreover, with more burdens being shared, there is the moral hazard problem that people might take less care to meet their deadlines or save money, and less willing to endure discomfort. This gives you reasons not to want to live in a society that has very expansive emergency norms. You want to limit emergency norms to cover predominantly cases that are relatively serious, rare, and unexpected, so you do not have to assist all the time.

\section{The informal-insurance model and common-sense emergency norms}

If we understand emergency norms as informal insurance schemes, the example of a person drowning in a shallow pond would be close to an archetypical example of what would be covered by emergency norms. The reason is that this is a very serious danger, it happens unexpectedly, it can only be solved through an immediate response from people nearby, and once someone is saved from drowning, they will usually be right back at their normal level of functioning.

What about someone risking malaria infection due to a lack of bednets? Even though dying from malaria is as bad as dying from drowning, there are some 
notable differences. First, the need for bednets does not arise unexpectedly; it is a need that we can know beforehand. Moreover, the problem can, in principle, be solved by anyone who has sufficient funds to make a donation to the Against Malaria Foundation. Finally, even if someone is saved from a malaria infection in virtue of getting a bednet, the lack of bednets is a symptom of a more general problem, poverty, and this would be a continuing problem even after one receives a bednet.

Should we seek to solve predictable and constant problems, such as problems caused by poverty, through emergency responses? Unger asks us to imagine a future where "whenever well-off folks learn of people in great need, they promptly move to meet the need, almost no matter what the financial cost." 14 This may at first glance seem like a utopia, but if we had a duty to rescue every time we learned that someone in poverty, we would, at least in today's world, all be living in a constant emergency. If we always had to rush to help, it would be very difficult to function as friends, parents, or productive members of society, and this, in turn, could have very serious negative effects in the long term. ${ }^{15}$ It seems that when it comes to solving predictable and constant problems, it is usually more advisable that we do so through institutions rather than through making emergency norms more expansive.

Admittedly, you might have strong duties of beneficence to help people cope with predictable and constant problems. Thus you might have a duty to donate a substantial portion of your income to an effective charity. We suggest, however, that when it comes to your duty to save a person drowning in a shallow pond, this is not a duty that is merely, or even predominantly, a duty of beneficence. While your duties of beneficence do count in favor of saving the person, so does the fact that this is an emergency. When you are called on to save the person about to drown in a shallow pond you are called on to pay the premium on an informal insurancescheme from which you also benefit, since the scheme makes your own life less risky than it would otherwise have been. ${ }^{16}$ This could explain why failing to save a person drowning in a shallow pond is rightly condemned much more harshly than failing to donate money to the Against Malaria Foundation. Someone who fails to save a person drowning in a shallow pond attempts to freeride on, and thus acts in a way that undermines, a life-saving scheme.

What about the Rolex case? Given the informal-insurance model, we should expect our emergency norms not to permit a person to drive past a person drowning in a shallow pond in order to sell a Rolex and give the money to charity. The person drowning in a shallow pond can most likely be saved by only one, or only by very

\footnotetext{
14 Unger (1996, 20).

15 A similar point is made by Schmidtz (2009).

16 Admittedly, there is something out of the ordinary with the premium we pay in these cases. In other insurance schemes, we pay an annual fee that equals the value of the good multiplied with the likelihood of it being in need of replacement and receive full compensation if we need it. The cost is therefore small and distributed. As suggested by Haydar and Øverland (2019), this is also true for the expected cost in the case of emergencies. However, the realized cost is usually born by one person since we have no way of distributing the cost when the accident occurs. In short, we are both insurance holders and insurers in emergencies. This explains why duties in emergencies can be so demanding. The reason why we accept this heavy premium is because it is the only way to solve situations such as these.
} 
few, people, whereas any number of people could donate to charity. Moreover, we need emergency norms that make it difficult to freeride. Our emergency norms would collapse if we allowed people to fail to rescue by saying that they were on their way to donate their belongings. Emergency norms must require strict compliance.

Given the informal-insurance model, we should also expect our emergency norms not to oblige us to drive the CEO to the board meeting. It is important that we restrict the scope of help required by emergency norms to only get the person out of harm's way, since otherwise, the system would be too costly to be worth it. Even if it might be a nice gesture to offer to drive the CEO to the board meeting, this would not be mandated by emergency norms. Getting CEOs to board meetings, even important board meetings, is a need that CEOs must meet themselves or pay others to help them meet. Therefore, while it could arguably be contrary to emergency norms to refuse to drive him to an emergency room, it would not be contrary to emergency norms to refuse to drive him to the board meeting. ${ }^{17}$

What, then, about the Bugatti case, where the cost to the helper is their entire life savings? It could be argued that here the cost is too high for it to be reasonably required by an informal insurance scheme. To support this, it could be suggested that it is much less clear that one is required to lose a limb in order to save a life, even though it seems that, in a range of cases, many people would rather lose a limb than to lose their life savings. ${ }^{18}$

In responding to this, it should be conceded, first, that the larger the required sacrifice, the stronger are our reasons not to include it in the informal-insurance scheme. We would also like to point out that, for all we argue here, to require that someone sacrifices their life savings might indeed be to require too much; the informal-insurance model that we defend does not, after all, depend on the view that this should be required. That said, however, we would like to suggest that the need to make quick decisions in emergency situations counts in favor of not having an upper limit on the cost of material sacrifices that have to be made, if necessary, in order to save a life. For emergency norms to work, they need to be simple, and we don't want prospective helpers to engage in monetary calculations in life or death situations. As the Bugatti case makes clear, this seems to be in line with the common-sense view.

Another reason not to set an upper limit on cost of material sacrifices is that we can, as Bashar Haydar and Gerhard Øverland argue, compensate people who make such sacrifices afterwards. ${ }^{19}$ If we were to construct an informal insurance scheme, it would be reasonable to agree to distribute particularly large costs among people who are not on the spot to help. Emergencies demand that the person in close

\footnotetext{
17 This may be another way of explaining the difference between preferences and need in Scanlon (1975).

18 We would like to thank an anonymous reviewer for both raising this issue and for pointing in the direction of how it should be handled. Harris (1975) argues in favor of how it can be rational to partake in a form of insurance scheme where you are guaranteed other people's body parts in exchange for having to give up your own.

19 Haydar and Øverland (2019).
} 
proximity makes the sacrifice there and then, but so as to not deter potential helpers, the helpers should not have to bear the full financial cost. Emergency norms should therefore include a rule of reimbursement, ideally from the community, at least to the extent that this is something that the community can reasonably afford, for their material loss. The thought experiment with the Bugatti is somewhat contrived in that it explicitly rules out the possibility of any reimbursement of the financial loss.

While it makes sense to have a norm that does not place an upper limit to material wealth that must be sacrificed to save a life in an emergency, it also makes sense that we treat the sacrifice of a part of one's body differently. This is a type of sacrifice that, in a larger number of cases, will be too big to be reasonably required, and it will often involve a significant risk of death on the part of the helper. Moreover, whereas monetary losses can be fully redeemed afterwards by having everyone in the community pay a small sum, the loss of a limb cannot be redeemed in this way. ${ }^{20}$

In light of the way the informal-insurance model can handle these cases, it seems that it can explain both the force-how much weight we should put on this duty relative to other concerns-and the scope-to what set of cases does the duty apply_of our duties of rescue in emergencies, something which few, if any, accounts have managed. ${ }^{21}$ The model predicts that the more the risks tends to be equally distributed, the lower the risk of moral hazard, and the fewer ways we have to solve this type of problem through formal institutions, the higher the likelihood that it is sought solved through emergency norms.

\section{The informal-insurance model and theoretical simplicity}

Having considered the ways in the informal-insurance model predicts commonsensical emergency norms, let us now turn to how the model can help justify common-sense emergency norms within a theoretically simple framework.

One such framework is contractualism, according to which we have a moral duty to act the way it is rational for people to commit to act, or that it would be rational for people to agree to act behind a veil of ignorance, if others agree to do the same. ${ }^{22}$ Contractualism would mandate compliance with emergency norms insofar as reasonable people agree to pay the premium of having to help others in emergencies in exchange for the security of having helpers at one's disposal if need be. This, moreover, is a way to defend common-sense emergency norms while preserving theoretical simplicity. On a contractualist view, the normative principle is simple. The complexities that arise in emergencies are the result of game-theoretical complexities involved in human interaction.

Another such framework is rule-consequentialism, according to which we have a duty to act in the way that, if everyone acted this way, would be likely to create the

\footnotetext{
${ }^{20}$ Haydar and Øverland (2019).

21 See Rulli and Millum (2016).

22 See Scanlon (1998).
} 
best possible outcome. Rule-consequentialism would mandate compliance with common-sense emergency norms insofar as compliance would create the best possible outcome, which is another way to justify common-sense emergency norms without a complex set of normative principles. $^{23}$

Might the informal insurance model also justify common-sense emergency norms within an act consequentialist framework, which is arguably the very simplest normative framework? According to act consequentialism, we should act in the way that is expected to create the best possible consequences. This is the view of Singer and Unger, and as we saw above, there seems to be some tension between this framework and common-sense emergency norms. It seems that, on this view, it would be equally important to save a person from malaria as to save a person drowning in a shallow pond. Moreover, since all that matters, always, is to act to create the best possible future, it seems that act-consequentialists would have to say that a person could have a duty to drive by a person drowning in a shallow pond in order to sell a Rolex and to drive the CEO to the board meeting if it is very important that he gets there.

Act consequentialism certainly entails that, seen in isolation, you should indeed do these things, given that you would in fact produce the most overall good that way. However, in a complex and non-transparent world like ours, act consequentialists have strong reasons to defer to norms we expect to produce most good. This is all the more important when we think about all the self-serving biases that affect our thinking. Since we don't know the full consequences of our actions, and we have a tendency to use agential leeway to benefit ourselves and the people we care most about, act consequentialists should require extremely strong reasons before breaking emergency norms. ${ }^{24}$

Moreover, even in a case where one was in fact justified in driving by the drowning person to sell the Rolex, other consequentialists would be wise to blame them, and perhaps legally prosecute them, for breaking the emergency norms that we depend upon for our safety. A way to describe the action of the consequentialist in cases where disregarding an emergency is the right thing to do is blameworthy rightdoing, in contrast to blameless wrongdoing. ${ }^{25}$

It could be objected that if we accept this, we come dangerously close to adopting a rule-consequentialist or even a nonconsequentialist view. ${ }^{26} \mathrm{We}$ would like to stress, however, that what nevertheless distinguishes the act consequentialist view from these alternatives is that it says that if you are sufficiently certain that rescuing someone will be for the worse all things considered, act consequentialism dictates that you should break the norm. One could, e.g., crank up the numbers in the Rolex case to see the intuitive plausibility of this view: If you could save the lives of one

\footnotetext{
${ }^{23}$ See Hooker (2000).

24 For this type of defense of consequentialism, see Railton (1984), and Pettit (1997), and Mason (1999).

25 Tännsjö $(2017,193)$.

26 Our account of emergency norms as informal insurance schemes can even be said to have certain structural similarities with nonconsequentialist theories of emergencies that see emergencies as the residual individual obligations we have when other collective obligations fail to deliver needed results. See Sinclair (2018, 51-52) and Herman (2012, 408-409).
} 
thousand faraway people over the next year by letting one child drown right here and now, that would arguably be the right thing to do.

Nevertheless, insofar as act-consequentialists would be well advised to endorse common sense emergency norms, and act to uphold such norms in society, it can serve as a theoretically simple foundation for justifying common sense emergency norms.

\section{Conclusion}

In this paper we have argued that emergency norms are informal insurance schemes, and that this model can help us combine common-sense emergency norms with theoretically simple normative frameworks, including contractarianism, ruleconsequentialism, and act-consequentialism.

An implication of this view is that whether a situation is an emergency does not depend merely on how bad the situation is; it also depends on whether it is bad in a way that it is effective to seek to solve through an informal insurance scheme that requires bystanders to step out of their ordinary routines in order to offer immediate assistance. Since we cannot function in a constant emergency, constant and predictable needs are usually best met institutionally.

The view that we defend should be taken as a cautionary note for philosophers who use emergency cases to test our general ethical principles. Our duties in emergencies can be extremely demanding, which they must be to ensure that people get help in situations we are unable to prevent and where we are unable to help ourselves. We should therefore not use our demanding duties in emergencies as evidence for equally strong duties in nonemergency situations.

Acknowledgements For comments on previous versions of this article, we are grateful to audiences at University of Oslo, Norwegian University of Science and Technology, and Roskilde University. We would particularly like to thank Andreas Kotsadam, Sadie Regmi, Aleksander Sørlie, Sune Lægaard, Ainar Petersen Miyata, Joona Räsanen, Alexander R. Cohen, and two anonymous reviewers. Work on this paper was funded by the Research Council of Norway, Project 259521.

Open Access This article is licensed under a Creative Commons Attribution 4.0 International License, which permits use, sharing, adaptation, distribution and reproduction in any medium or format, as long as you give appropriate credit to the original author(s) and the source, provide a link to the Creative Commons licence, and indicate if changes were made. The images or other third party material in this article are included in the article's Creative Commons licence, unless indicated otherwise in a credit line to the material. If material is not included in the article's Creative Commons licence and your intended use is not permitted by statutory regulation or exceeds the permitted use, you will need to obtain permission directly from the copyright holder. To view a copy of this licence, visit http:// creativecommons.org/licenses/by/4.0/. 
Funding Open Access funding provided by OsloMet - Oslo Metropolitan University. Open Access funding provided by the Research Council of Norway.

\section{References}

Bentham, J. (1804). Means of extraction for extraordinary occasions. University College London Library, Bentham Papers 74b/428-33.

Foot, P. (1967). The problem of abortion and the doctrine of double effect. Oxford Review, 5, 5-15.

Hanna, R. (1998). Must we be good samaritans? Canadian Journal of Philosophy, 28(3), 453-470.

Harris, J. (1975). The survival lottery. Philosophy, 50(191), 81-87.

Haydar, B., \& Øverland, G. (2019). Hypocrisy, poverty alleviation, and two types of emergencies. Journal of Ethics, 23(1), 3-17.

Herman, B. (2012). Being helped and being grateful: Imperfect duties, the ethics of possession, and the unity of morality. Journal of Philosophy, 109(5-6), 391-411.

Hooker, B. (2000). Ideal code, real world: A rule-consequentialist theory of morality. Oxford: Oxford University Press.

Kamm, F. (2007). Intricate ethics. Oxford: Oxford University Press.

Levinas, E. (1995). Ethics and infinity: Conversations with Philippe Nemo. Pittsburgh: Duquesne University Press.

Mason, E. (1999). Do consequentialists have one thought too many? Ethical Theory and Moral Practice, 2(3), 243-261.

Pettit, P. (1997). A consequentialist perspective on ethics. In P. Pettit (Ed.), Three methods of ethics: A debate. Oxford: Blackwell.

Railton, P. (1984). Alienation, consequentialism, and the demands of morality. Philosophy \& Public Affairs, 13(2), 134-171.

Rand, A. (1964). The ethics of emergencies. In The Virtue of Selfishness: A New Concept of Egoism. New York: New American Library.

Rulli, T., \& Millum, J. (2016). Rescuing the duty to rescue. Journal of Medical Ethics, 42, 260-264.

Scanlon, T. M. (1975). Preference and Urgency. Journal of Philosophy, 72(19), 655-669.

Scanlon, T. M. (1998). What we owe to each other. Cambridge, MA: Belknap Press.

Schmidtz, D. (2000). Islands in a sea of obligations: Limits to the duty of rescue. Independent Institute Working Paper \#18. Retrieved Feb 9, 2020 from https://www.independent.org/pdf/working_papers/ 18_islands.pdf.

Schmidtz, D. (2009). Separateness, suffering, and moral theory. In J. D. Schaler (Ed.), Peter Singer under fire: The moral iconoclast faces his critics. Chicago: Open Court Publishing Company.

Sinclair, T. (2018). Are we conditionally obligated to be effective altruists? Philosophy \& Public Affairs, 46(1), 36-59.

Singer, P. (1972). Famine, affluence, and morality. Philosophy \& Public Affairs, 1(3), 229-243.

Tännsjö, T. (2017). The hedonistic utilitarian. In R. Marshall (Ed.), Ethics at 3:AM: Questions and answers on how to live well. Oxford: Oxford University Press.

Temkin, L. (2017). Uehiro Lectures 2017. The Oxford Uehiro Centre for Practical Ethics. Retrieved Feb 26, 2020 from https://www.practicalethics.ox.ac.uk/uehiro-lectures-2017.

Unger, P. (1996). Living high and letting die. Oxford: Oxford University Press.

Waldron, J. (2000). On the road: Good samaritans and compelling duties. Santa Clara Law Review, 40(4), $1053-1103$.

Wiblin, R. (2017). Most people report believing it's incredibly cheap to save lives in the developing world. 80,000 Hours. Retrieved Feb 9, 2020 from https://80000hours.org/2017/05/most-peoplereport-believing-its-incredibly-cheap-to-save-lives-in-the-developing-world/.

Woollard, F. (2015). Doing and allowing harm. Oxford: Oxford University Press.

Publisher's Note Springer Nature remains neutral with regard to jurisdictional claims in published maps and institutional affiliations. 